\title{
Prevention and Care for Incontinence-Associated Dermatitis Among Older Adults: A Systematic Review
}

\author{
Samoraphop Banharak (iD) \\ Ladawan Panpanit' \\ Suttinan Subindee' \\ Patcharawan Narongsanoi ${ }^{2}$ \\ Panisara Sanun-aur ${ }^{3}$ \\ Walaiporn Kulwong ${ }^{4}$ \\ Pachareeporn Songtin ${ }^{5}$ \\ Wanida Khemphimai ${ }^{6}$ \\ 'Department of Gerontological Nursing, \\ Faculty of Nursing, Khon Kaen University, \\ Khon Kaen, Thailand; ${ }^{2}$ Nursing Department, \\ Maharat Nakhon Ratchasima Hospital, Nakhon \\ Ratchasima, Thailand; ${ }^{3}$ Nursing Department, \\ Bungkla Hospital, Buengkan, Thailand; ${ }^{4}$ Nursing \\ Department, Banmuang Hospital, Sakon Nakhon, \\ Thailand; ${ }^{5}$ Nursing Department, Nong Han \\ Hospital, Udon Thani, Thailand; ${ }^{6}$ Nursing \\ Department, Phimai Hospital, Nakhon \\ Ratchasima, Thailand
}

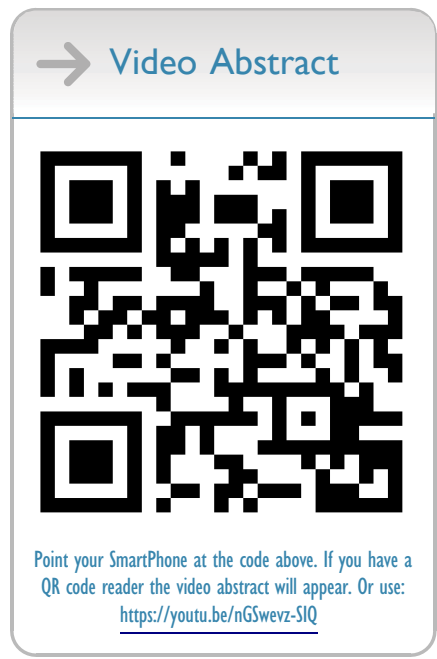

Correspondence: Samoraphop Banharak Department of Gerontological Nursing, Faculty of Nursing, Khon Kaen University, 123 Moo 16 Friendship Road, Khon Kaen, 40002, Thailand

Tel +66 6l-930-8II 8

Fax +66 43-424-809

Email sbanharak@kku.ac.th
Background: The prevalent rate of incontinence-associated dermatitis (IAD) trends upward in older populations. Skin breakdown from IAD impacts the quality of life of older adults and reflects the quality of care in hospitals and long-term care facilities. Specific and appropriate interventions for prevention and care are needed. This systematic review aims to review optimal strategies for prevention and care for older adults with IAD.

Methods: PubMed, CINAHL, SCOPUS, Medline, ProQuest, ThaiLIS, ThaiJo, and E-Thesis were searched for articles published between January 2010 and December 2020. Only articles focusing on older adults were included for the review.

Results: Eleven articles met the inclusion/exclusion criteria. Interventions for the prevention and care of IAD among older adults were categorized as assessment, incontinence management/ causative factors management, cleansing, application of medical products for both skin moisturizing and skin barrier, body positioning, nutrition promotion, health education and training, and outcome evaluation. Specific prevention and care strategies for older adults with IAD included using specific assessment tools, applying skin cleansing $\mathrm{pH}$ from 4.0 to 6.8 , body positioning, and promoting food with high protein. Other strategies were similar to those reported for adult patients. Conclusion: The systematic review extracted current and specific prevention and care strategies for IAD in older adults. The prevention and care strategies from this systematic review should be applied in clinical practice. However, more rigorous research methodology is recommended in future studies, especially in examining intervention outcomes. Nurses and other health professionals should be educated and trained to understand the causes of IAD in older adults and the specific prevention and care strategies for this population. Because older adults are prone to skin damage, and this type of skin breakdown differs from pressure ulcers, the tools for assessment and evaluation, and the strategies for prevention and care require special attention.

Prospero Registration Number: CRD42021251711.

Keywords: incontinence-associated dermatitis, moisture-associated skin damage, skin barrier function, skin breakdown, older adults, systematic review

\section{Introduction}

Incontinence-associated dermatitis (IAD) is a type of moisture-associated skin damage (MASD) caused by physical and chemical irritants. ${ }^{1}$ Older adults are prone to skin damage, especially when hospitalized in semi-intensive care units, intensive care units, or living in long-term care facilities. ${ }^{2}$ When exposed to urine and fecal matter, the skin becomes erythematous with the potential of developing dermal and epidermal erosion. ${ }^{3}$ The combination of an alkaline $\mathrm{pH}$ and noxious chemical irritants can stimulate the skin to erode. Damage to the skin can occur within 10-15 minutes following contact 
with moisture from stool or urine, causing overhydration and a slight swelling. ${ }^{4}$ In addition, the presence of friction and shear mechanical forces can decrease skin functioning and cause skin injury. ${ }^{1,2,5}$ Thus, the potential for skin breakdown among incontinent older adults requires careful assessment and care.

The prevalence and complications related to IAD trend upward in older populations. The prevalence of all types of incontinence in older adult age $\geq 65$ years has been reported by a multisite study as $28.3 \%$, with $18.2 \%$ for urinary incontinence, $2.3 \%$ for fecal incontinence, and $7.8 \%$ for dual incontinence. ${ }^{6}$ Another multisite study found $46.6 \%$ of the patients had urinary, fecal, or dual incontinence. ${ }^{7}$ Elsewhere, researchers reported that over $10 \%$ of the population experienced urinary incontinence. Of those, $15 \%$ were healthy older adults and $65 \%$ were frail older adults. Fecal incontinence has been reported to be from $1 \%$ to $10 \%$ of healthy older adults and from $17 \%$ to $66 \%$ of hospitalized older patients. ${ }^{1,4}$ Urinary and fecal incontinence caused IAD in $33 \%$ of the hospitalized patients and $41 \%$ of residents in long-term care facilities. ${ }^{4}$

Gray and Giuliano (2018) reported that the prevalence of IAD among persons with any type of incontinence was $45.7 \%$. Over $25 \%$ was present on admission and $73 \%$ was acquired during hospitalization. The clinical characteristics of IAD were $52.3 \%$ mild, $27.9 \%$ moderate, and $9.2 \%$ severe, with $14.8 \%$ also having a fungal rash (secondary infection). ${ }^{7}$ Incontinence, especially dual incontinence, were 1.63 to 1.64 times more likely to develop from a facility-acquired pressure injury compared with those with no incontinence. ${ }^{6,7}$ These statistics reflect the importance of assessing and caring for older adults who are prone to develop and suffer from IAD. ${ }^{8-10}$

As people age, the skin becomes more susceptible to breakdown because of the aging processes. These include the loss of connective tissue and collagen, the flattening of dermal papillae, and the cross-linking inside the structure of elastin that can decrease the skin's elasticity. ${ }^{2}$ As the skin ages, the epidermis thins and loses some of its elasticity, cell turnover is reduced, and the skin becomes more fragile. As a result, the skin is drier, more fragile, and prone to injury from excessive moisture. ${ }^{1,2}$ A high incident rate of incontinence and degeneration of skin among older adults makes them at risk of IAD. When older adults experience urinary and fecal incontinence together with the aging processes, the combination of noxious chemicals and moisture stimulates IAD. ${ }^{8,10}$ Therefore, older adults' skin becomes more susceptible to breakdown, leading to a higher incident rate of IAD in this population.

There are serious complications and negative outcomes from IAD. Skin damage to older adults causes not only physical and mental suffering, and the potential of secondary infections, but also increases the costs of care and longer lengths of stay. ${ }^{5}$ For example, Lumber (2019) reported that IAD patients' symptom severity can range from a low level, such as feeling uncomfortable, to a high level, such as excessive painful ulceration. IAD was one significant factor in causing secondary infection with an increased susceptibility to pressure ulceration. ${ }^{2}$

Pressure ulcers and secondary infection cause longer lengths of stay and higher costs of care. ${ }^{4}$ In one financial study of IAD, the estimated product cost ranged between US\$0.05 and $\$ 0.52$ per application for prevention and between $\$ 0.20$ and $\$ 0.35$ for treatment. The product cost for prevention ranged between $\$ 0.23$ and $\$ 20.17$ per patient/day. The product cost of IAD prevention and treatment per patient/day ranged between $\$ 0.57$ and $\$ 1.08 .^{11}$ Moreover, medications used to treat these two conditions can cause iatrogenesis, such as drug interactions and side effects of treatment. ${ }^{2,5}$

First line prevention before the occurrence of these complicated problems is recommended. However, some people may already have IAD when they are admitted to a hospital or long-term care facility. The previously mentioned multisite study found that $25.1 \%$ of IAD was present on admission. ${ }^{7}$ In this case, both prevention and care strategies of IAD should be implemented. ${ }^{1}$

Several studies and systematic reviews have been conducted, and general prevention and care guidelines for IAD have been recommended. ${ }^{4,5,9,12-17}$ Beeckman et al (2016) reported that the principles of prevention and care for IAD are cleansing, moisturizing, and protecting. ${ }^{12}$ Others have provided details about general prevention and care guidelines, such as skin assessment, skin cleaning, skin barrier, containment device, and treatment of secondary infection. ${ }^{4,5}$ However, their populations were adult or pediatric patients.

What is lacking is a specific comprehensive review and strategic synthesis of various options for older adults. Health care providers need to evaluate multiple options and interventions applicable to their populations of interest, especially older adults. Therefore, in conducting a systematic review, we sought to answer a clinically important question: What are the specific and appropriate interventions required to prevent and care for older adults with 
IAD? The aim was to provide a comprehensive review of specific strategies for both the prevention and care of older adults with IAD.

\section{Materials and Methods Design}

A systematic review with narrative summary was undertaken. We conducted the review using the Preferred Reporting Items of Systematic Reviews and MetaAnalysis Protocols (PRISMA-P) checklist guidelines and the standardized critical appraisal instruments from the Joanna Briggs Institute (JBI). Our processes were started by formulating the review question and aim, defining the inclusion and exclusion criteria, developing the search strategy, locating and selecting relevant articles, assessing their quality, extracting data, and analyzing and interpreting the results. ${ }^{18}$ The protocol to conduct the systematic review was published and registered with PROSPERO (CRD42021251711).

\section{Search Strategy}

We searched for empirical articles published between January 2010 and December 2020 in eight databases: PubMed, CINAHL, SCOPUS, Medline, ProQuest, ThaiLIS, ThaiJo, and E-Thesis. An ancestry search of the references of identified studies was also conducted, including a manual search of journals. The following search terms were used to access all possible and matched studies: "incontinence associated dermatitis" OR IAD OR "incontinence-associated dermatitis" OR "moisture associated skin damage" OR "diaper dermatitis" OR "perineal skin injury" OR "irritant contact dermatitis of the vulva" OR "skin breakdown" OR "skin barrier function*." The second group of keywords were intervention OR care OR prevention OR program OR protocol OR guideline OR treatment. The third group of keywords was "routine care" OR "usual care" OR "regular care." The three groups were combined using "AND."

Because we did not specify an older adult population as a search term, the results from the initial search mixed various age groups. This was an opportunity to appraise the studies more broadly. However, by subsequently applying the inclusion and exclusion criteria during the screening process, this allowed us to explore the germane research. Moreover, we took note of the multiple outcomes reported in the studies. Outcomes were typically reported and discussed in the studies' results and discussion sections.

\section{Inclusion and Exclusion Criteria}

Inclusion criteria were that the articles reported on research, projects, or were a review of the literature related to incontinence-associated dermatitis; focused on older adults (60 years or older) or reported interventions or management of older adults; published in English or Thai peer reviewed journals or thesis/dissertations; and available online in full text. Abstracts from academic conferences without full text were excluded.

\section{Data Extraction}

On the JBI data extraction form, ${ }^{18}$ we recorded the authors, types of articles, designs, settings, level and certainty of evidence, methodological quality, sample size, prevention and care strategies for IAD, and outcomes. Research notes were added for comments. Prior to starting the review, we practiced screening articles, extracting data, and assessing the quality together to make sure that the processes and results we had undertaken were accurate.

Of the eight reviewers, two were assigned to be a third opinion when reaching consensus. The other six reviewers were divided into three groups for screening and reviewing articles. First, they determined if studies met the inclusion/ exclusion criteria. Then, the selected articles were appraised by their respective JBI checklists. To be considered for review, we used a cut point positive appraisal (ie, "yes") for at least $50 \%$ of the items. Thereafter, we appraised the groups' assigned articles and extracted data (Figure 1). If a group's two reviewers could not agree on an appraisal, a third independent reviewer met with the group to reach consensus. The appraisal process was used to avoid errors and misinterpretations of research findings and to elevate the quality of the systematic review.

\section{Quality Appraisal}

We individually reviewed the selected articles under consideration using the respective JBI standardized critical appraisal checklists to assess the methodological quality of systematic reviews, ${ }^{19}$ randomized controlled trials (RCTs) ${ }^{20}$ texts and opinions, ${ }^{21}$ and case report studies. ${ }^{22}$ Methodological quality was graded into the four categories of very low, low, moderate, and high quality. ${ }^{23}$ Because the GRADE methodology is outcome centric, it was applicable only to the quantitative studies we found (ie, RCTs and cases studies) and not the review articles.

We developed a table to collect all relevant data from the studies, minimize the risk of errors in transcription, guarantee precision when checking information, and serve 


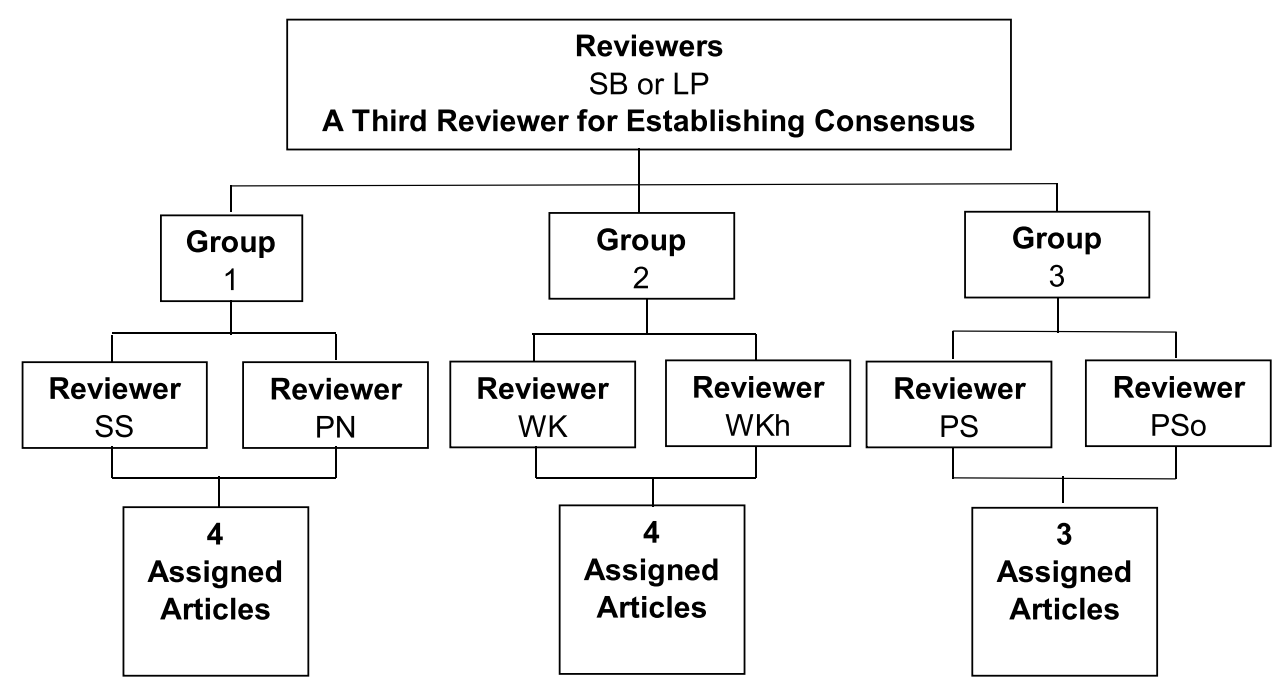

Figure I Diagram for group assignment and independent review.

as a record for the review. The table was also used to identify themes across the studies. Reviewers' comments and data recording were collected and organized using Mendeley reference manager software.

\section{Synthesis}

Extraction of quantitative data to conduct meta-analysis was not possible due to the small sample size, heterogeneity of the study population, different types of research design, outcomes measures, time of measuring, and data analysis across the studies. The results were placed in tabular and narrative form to include the studies' description, year, setting, design, sample size, prevention and care for IAD, and outcomes. A comment column was added for discussion and recommendation. We summarized the prevention and care strategies for IAD in older adults with additional discussion and suggestions.

\section{Results}

From the initial results of 17,631 articles, we screened the titles and abstracts of 9653 articles. Based on the inclusion/exclusion criteria and consensus among members of the research team, 11 articles were selected for the final comprehensive review, standardized critical appraisal, and synthesis. Figure 2 displays the PRISMA flow diagram of the information flow during the review process.

\section{Characteristics of the Articles}

Scores for the critical appraisal of the two RCTs were $10^{24}$ and $9^{25}$ out of a possible 13 points (Table 1). The critical appraisal score of the integrative review was 7 out of 11 possible points ${ }^{26}$ (Table 2). The critical appraisal scores of the six literature reviews were $4^{27}$ and $5^{2,8,28-30}$ out of a possible 6 points (Table 3 ). Scores for the two case reports were $5^{1}$ and $6^{10}$ out of an 8 possible points (Table 4). Four articles were graded for level of quality. Two of those had low methodological quality, ${ }^{1,10}$ and two had moderate methodological quality ${ }^{24,25}$ (Table 5).

Publication years for the 11 articles ranged from 2012 to 2020 . Two were in $2012 ;,{ }^{1,24}$ one in $2013,{ }^{26}$ three in $2017 ;^{25,27,28}$ two in $2018, ;^{29,30}$ two in $2019 ;^{2,8}$ and one in $2020 .^{10}$ Six articles were from the United Kingdom, ${ }^{1,2,8,10,29,30}$ two from Japan, ${ }^{24,25}$ two from Thailand, ${ }^{27,28}$ and one from a multi-site setting. ${ }^{26}$ The number of participants for the studies ranged from 3 to 1618 older adults. ${ }^{1,10,24-26}$ Because six studies were reviews of the literature, the authors did not report or need to report the participants ${ }^{2,8,27-30}$ (Table 6).

Of the five studies that indicated the participants' sex, two reported both males and females, ${ }^{1,26}$ whereas three focused only on female older adults. ${ }^{10,24,25}$ There were seven reviews and four research articles. Six articles were literature reviews with concluding text and opinions.${ }^{2,8,27-30}$ One article was an integrative review, ${ }^{26}$ whereas one article incorporated a mixed design using a literature review and case reports. ${ }^{1}$ One article was only a case report. ${ }^{10}$ Two articles were studies that used an RCT $\operatorname{design}^{24,25}$ (Table 6).

Interventions for prevention and care of IAD were categorized into eight groups: assessment, incontinence management/causative factors management, cleansing, medical products application, body positioning, nutrition promotion, health education and training, and outcomes 


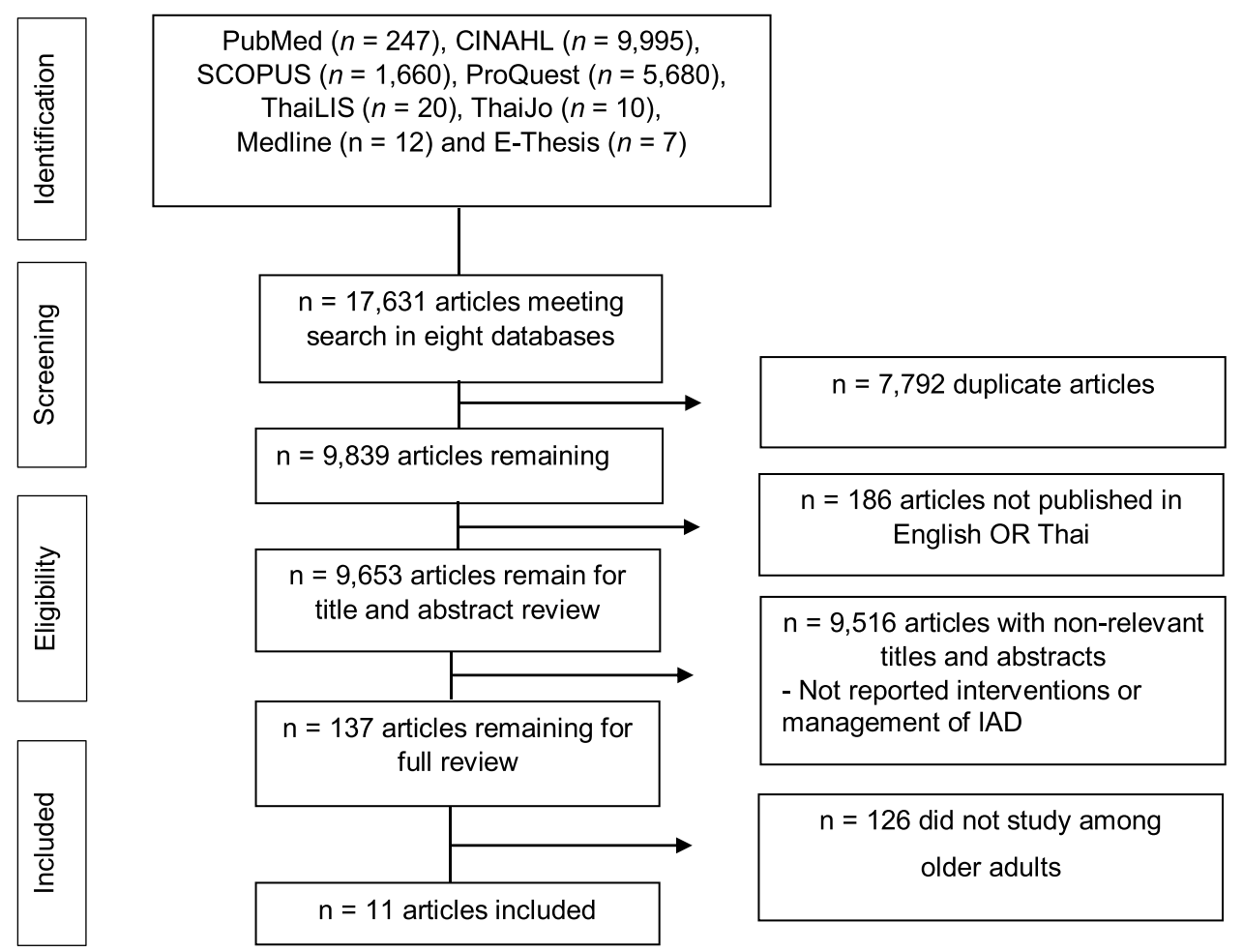

Figure 2 Flow chart of the review process and results.

Notes: Adapted from: Page MJ, McKenzie JE, Bossuyt PM, et al. The PRISMA 2020 statement: an updated guideline for reporting systematic reviews. BMJ. 202I;372:n7I. doi:10.1136/bmj.n7I. ${ }^{37}$ Creative Commons Attribution (CC BY 4.0) license (https://creativecommons.org/licenses/by/4.0/legalcode).

evaluation (Table 6). Finally, outcomes were reported for five studies. ${ }^{1,10,24-26}$ Details for each intervention and care are provided, as follows.

\section{Prevention and Care for Older Adults with IAD Assessment}

Assessment was an initial process either to identify the risk of IAD if it had not yet developed or to grade or determine the severity level of the IAD if it was present. Assessment was found in five articles. The following assessment tools were mentioned: Incontinence Assessment, IAD Risks Assessment, Skin Damage Assessment, Grade of Skin Damage, IAD Severity Instrument, Ghent Global IAD Categorization Tool, and Skin Moisture Alert Reporting Tool. ${ }^{1,10,28-30}$ Researchers and experts recommended that health care providers should start at assessment to seek for causes of incontinence, risks of $\mathrm{IAD}$, and levels of skin damage before planning to prevent and care for IAD. ${ }^{1,10,28-30}$ This would help health care professionals to identify the levels of risk and severity of IAD and to provide specific prevention and care strategies for each level of skin damage.

\section{Incontinence Management/Causative Factors Management}

Because prevention should be the major concern, managing IAD causative factors is the preferred strategy. Methods to manage incontinence and address causative factors were reported in eight articles. Example were the use of diapers, evacuation and urinary catheterization, absorbency and smooth pads, an improved aperture film plus a feminine pad, and a review of patient toileting techniques. However, some authors recommended using an appropriate containment or continence management system without giving the details of a guideline or explaining what the appropriate containment might be. $8,10,30$ Other authors provided more details about what interventions or products should be used to manage incontinence or prevent causative factors, such as diapers, ${ }^{28}$ evacuation and urinary catheterization, ${ }^{27}$ absorbency and smooth 


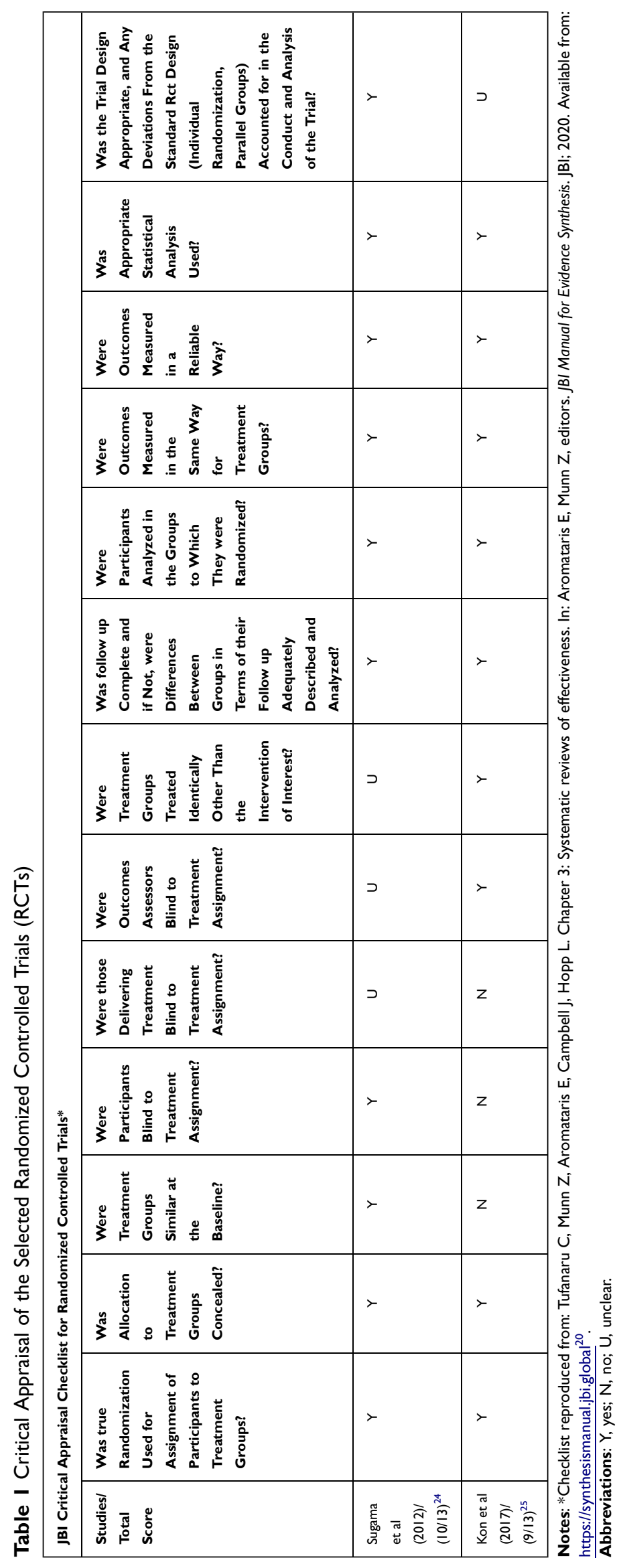




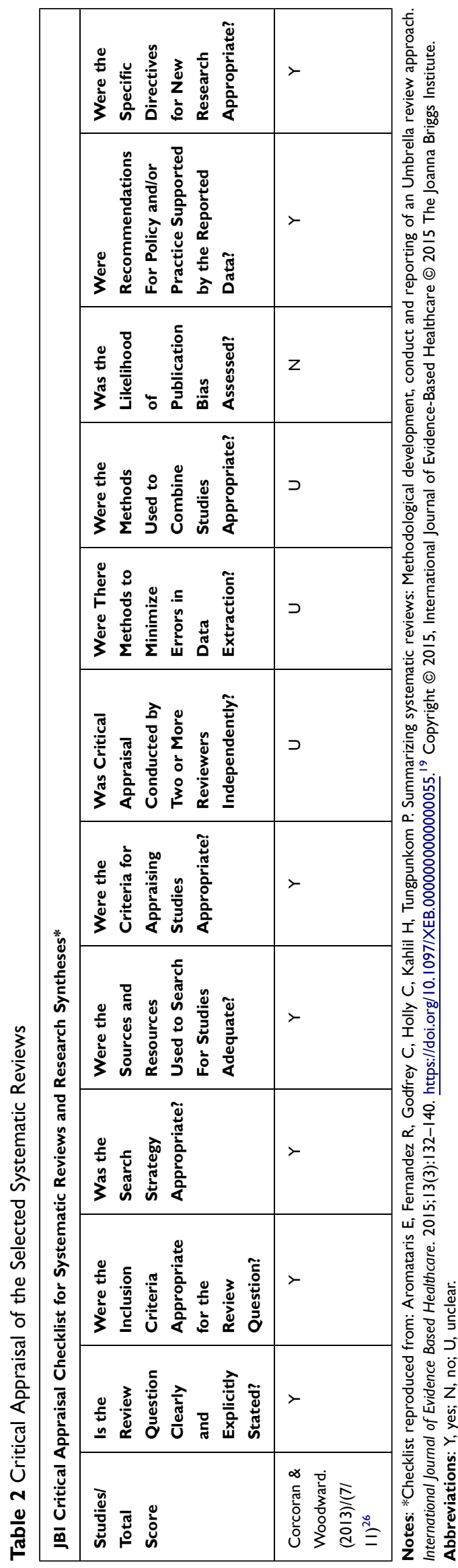

pads, ${ }^{29}$ an improved aperture film plus feminine pad, ${ }^{24}$ and a review of patient toileting techniques. ${ }^{2}$ However, Iamma (2017) points out that using a pad instead of a diaper is a better way to promote air flow and decrease the area of skin contact from urine and fecal matter. ${ }^{27}$ Most importantly, the use of an invasive technique in trying to control incontinence is not the first choice for managing IAD. ${ }^{2}$

\section{Cleansing}

The way to decrease chemical irritation and moisture damage to the skin is cleansing the affected area after each episode of urination and defecation. This process includes medical material removal, cleansing products, cleaning techniques, and water or waterless applications. Kliangprom and Putivanit (2017) state that a bandage or gauze dressing applied to the buttock area should remain in place for over 24 hours before removal and cleaning. Moreover, olive oil should be used to aid removing the bandage and peel back the bandage when removing it, not pulling upward on the skin. ${ }^{28}$ Cleansing should be started either immediately of incontinence, ${ }^{27,30}$ as quickly as possible, ${ }^{1,2}$ at least twice a day, ${ }^{28}$ or after each episode of incontinence. ${ }^{10,26}$ The cleansing product should not contain alcohol, chemical color, lotion, or perfume/ fragrance. ${ }^{27}$ Some authors suggested that the $\mathrm{pH}$ for skin cleansing should range from 4.0 to $6.8^{1,2,8,27,29,30}$ Soap and warm water, ${ }^{1,10,30}$ wet cloths and towels, ${ }^{10}$ and alkaline soap were not advised; ${ }^{30}$ however, Kon et al (2017) recommended using wet towels. ${ }^{25}$ If using soap, however, liquid soap for children was preferred. ${ }^{27}$ A disposable wash basin for cleaning the skin should be used to reduce cross infection. ${ }^{8}$ Rub, wipe, and rinse were actions to be avoided. ${ }^{27,28,30}$ In contrast, tapping technique and no-rinse cleansers, such as liquids, ${ }^{29}$ soaps, sprays, and foams, ${ }^{10}$ and gentle blotting of moisture ${ }^{27,28}$ should be used to reduce any cause or risks of skin breakdown. Examples of moisturizing and protective skin cleansers were provided. $^{10,25}$

\section{Medical Products Application}

Medical products are any products used to diagnose or manage older adults with IAD, including pharmaceutical products and medical devices. We found two groups of medical products mentioned by authors: skin moisturizers and skin barriers. ${ }^{8}$ The skin moisturizing products included a lotion without alcohol, chemical colors, or perfumes/fragrances; ${ }^{27}$ and moisturizers or emollients. ${ }^{29}$ The skin barriers could be creams, ointments, pastes, and 


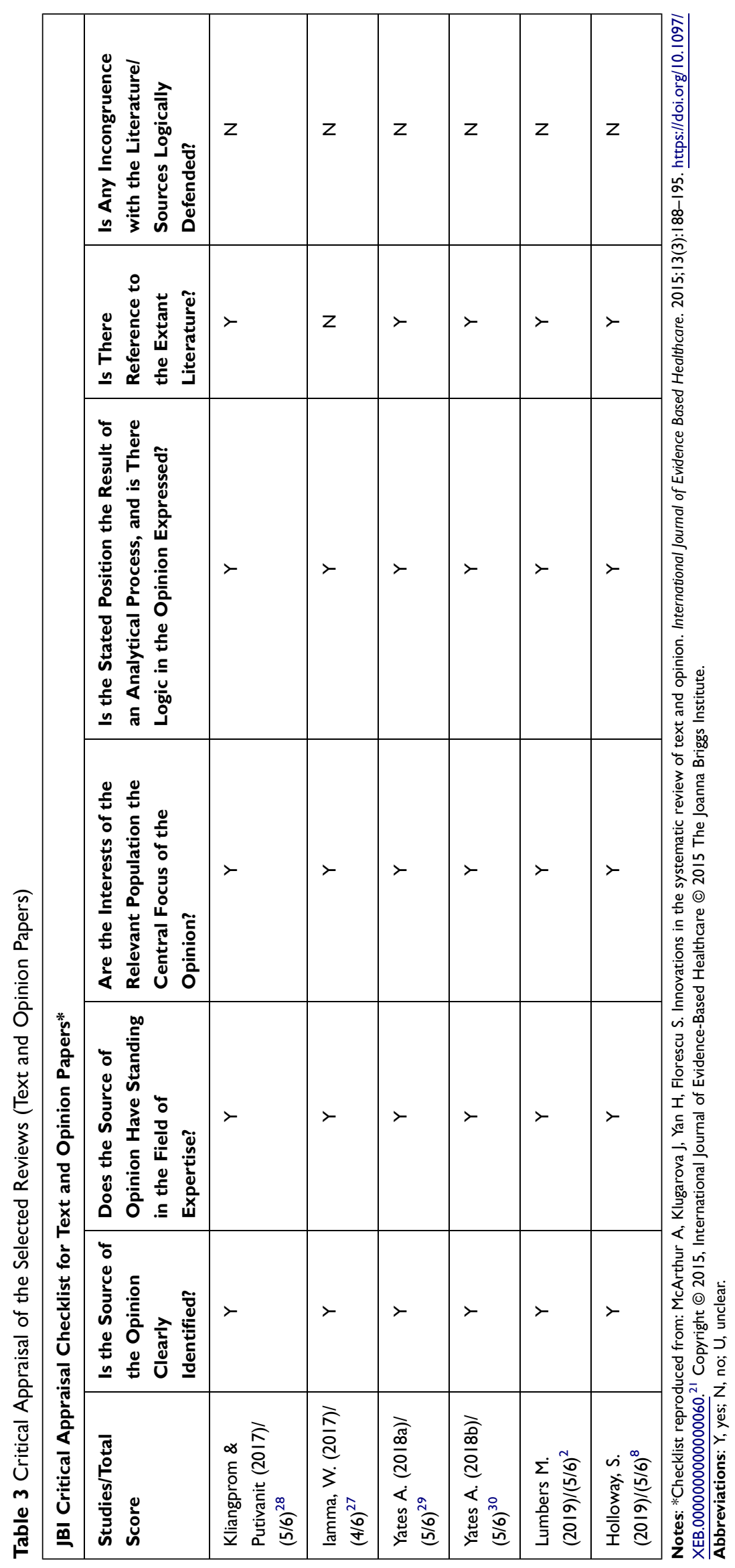




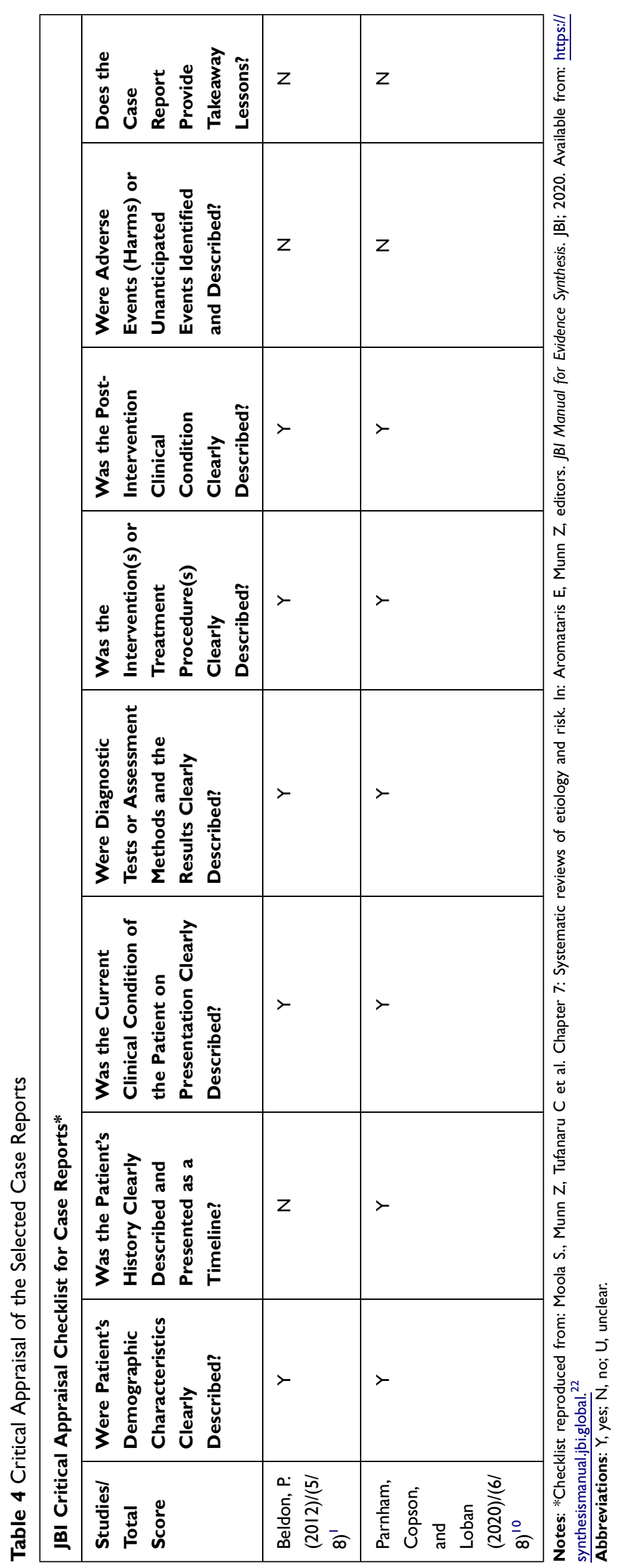




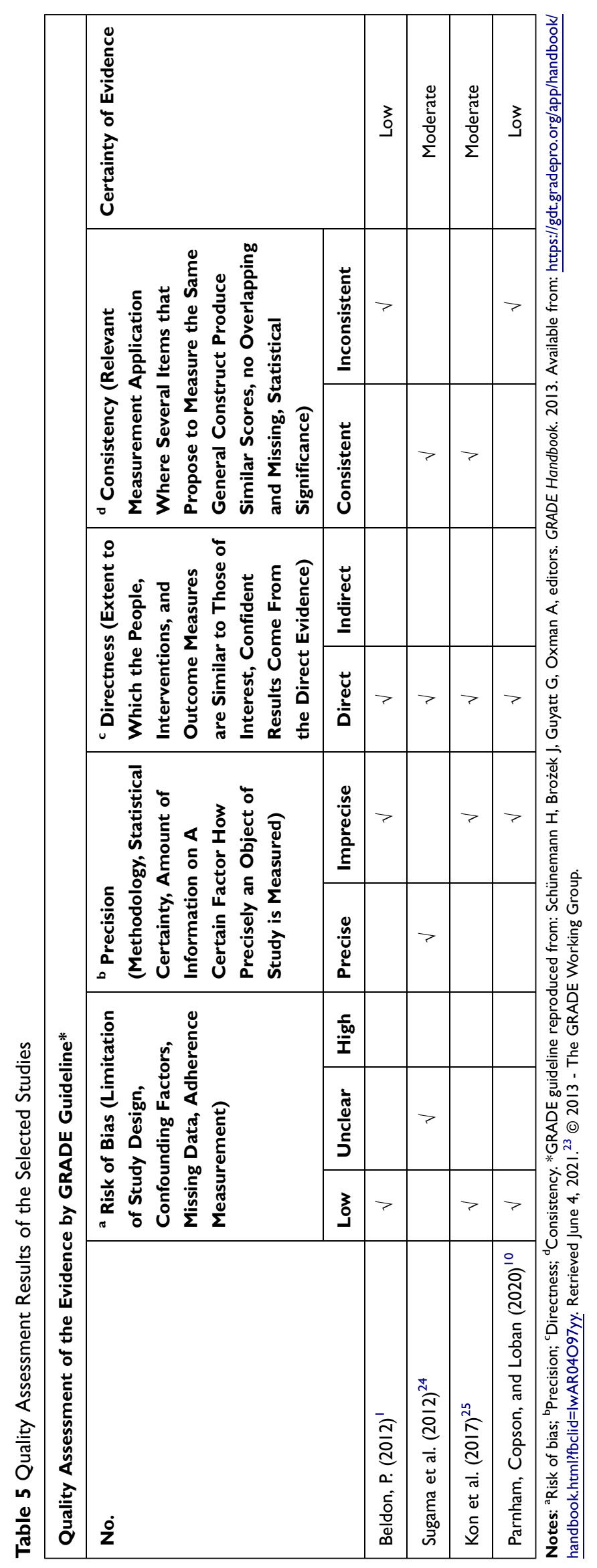




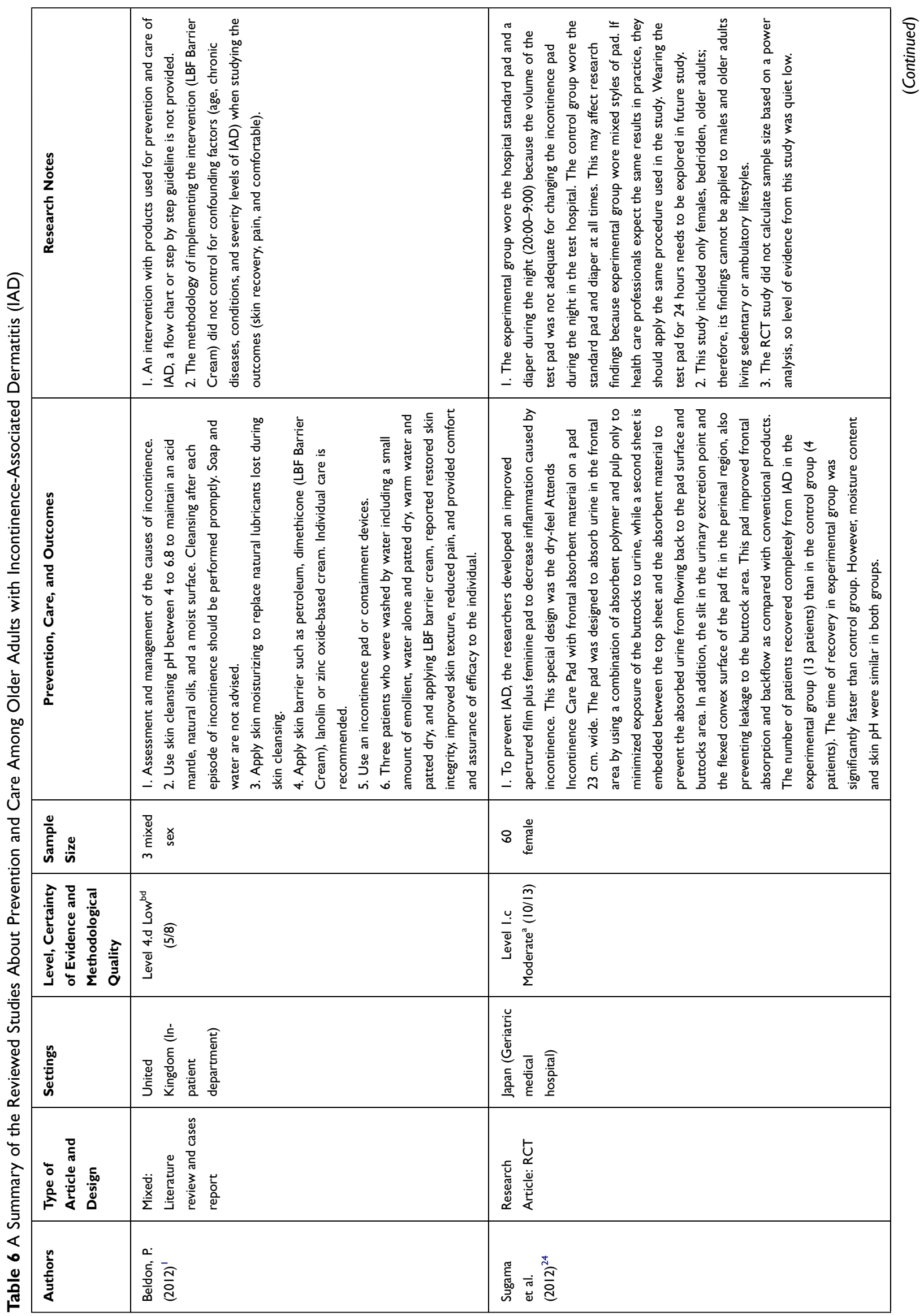




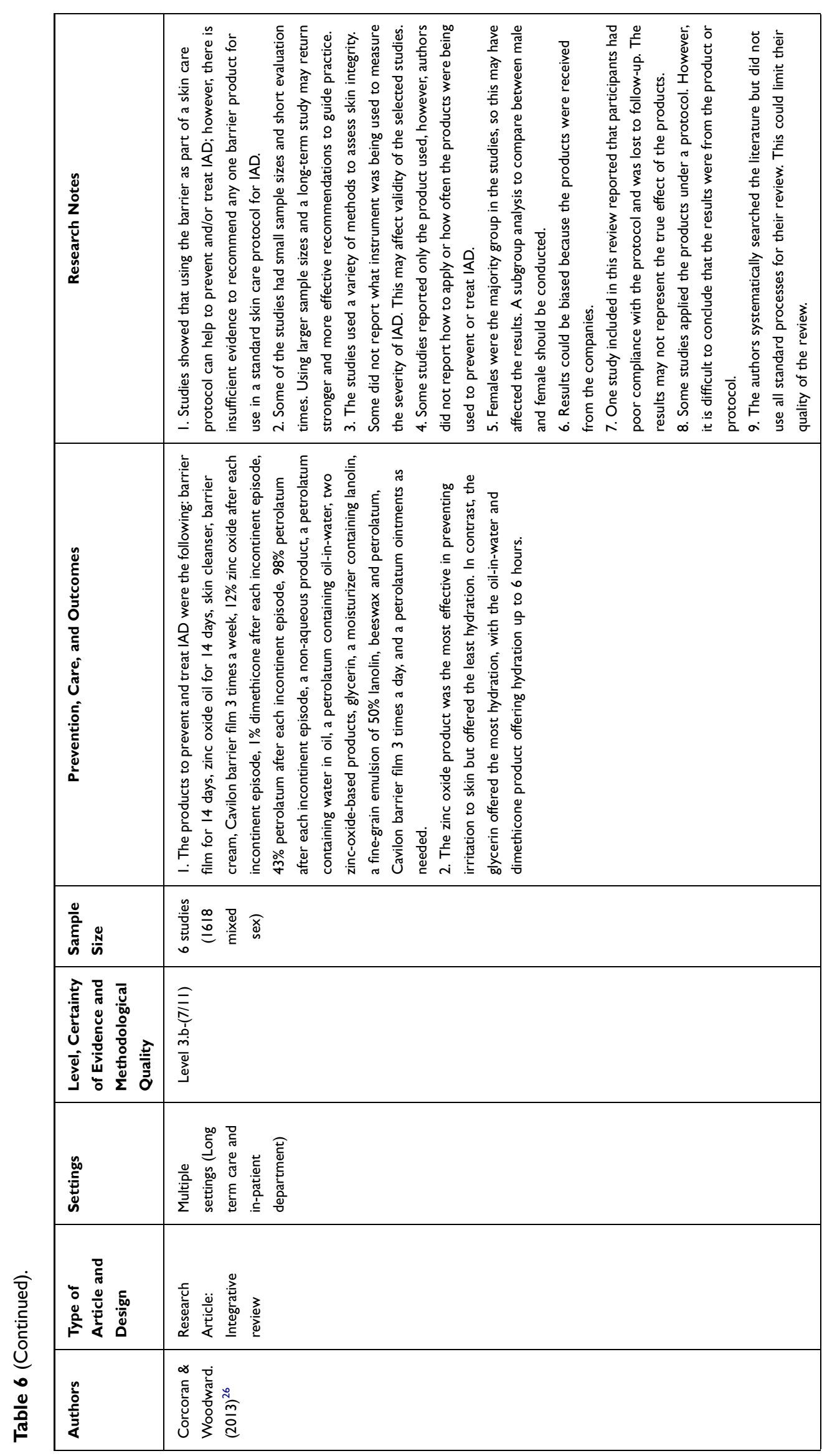




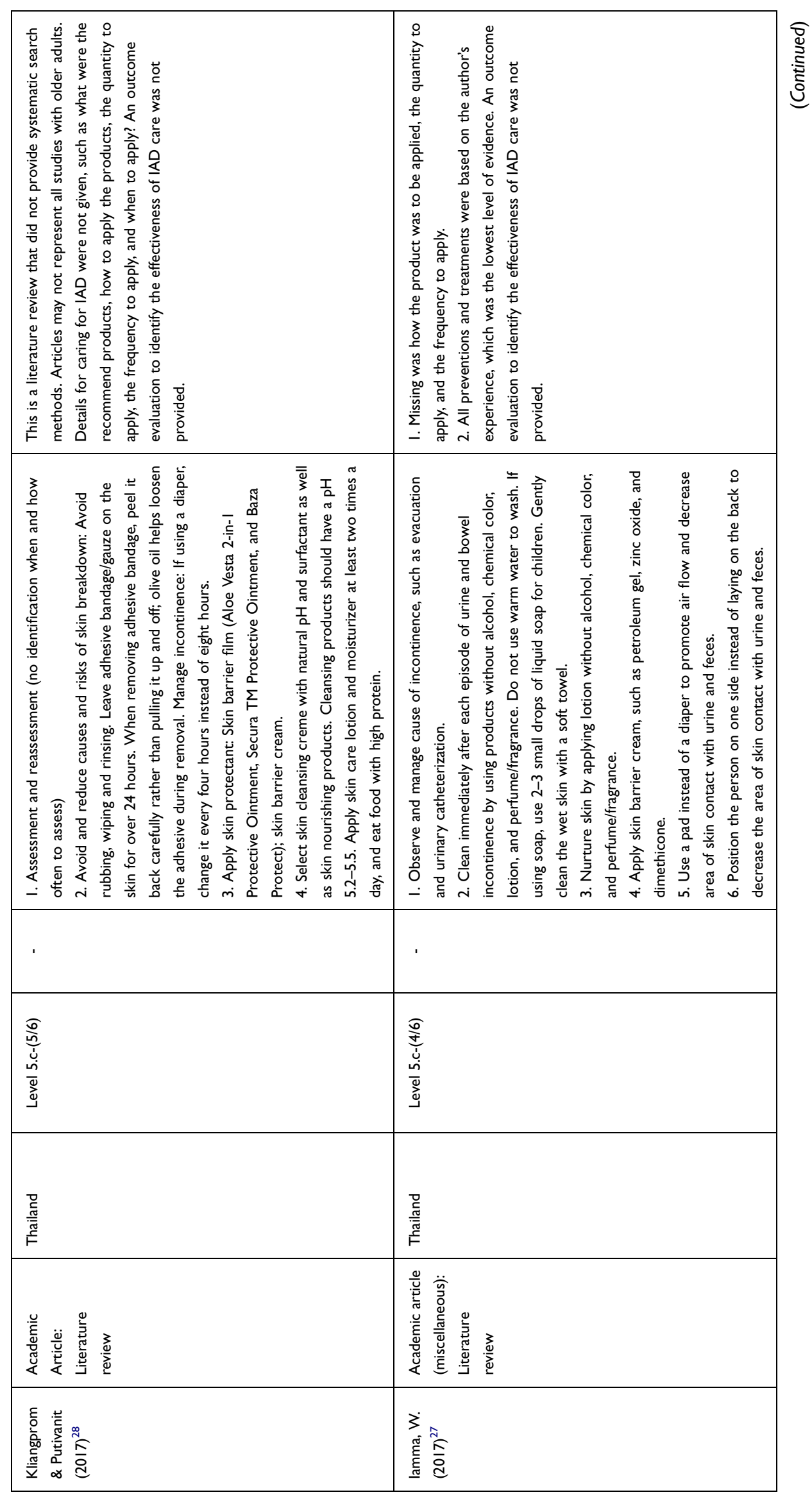




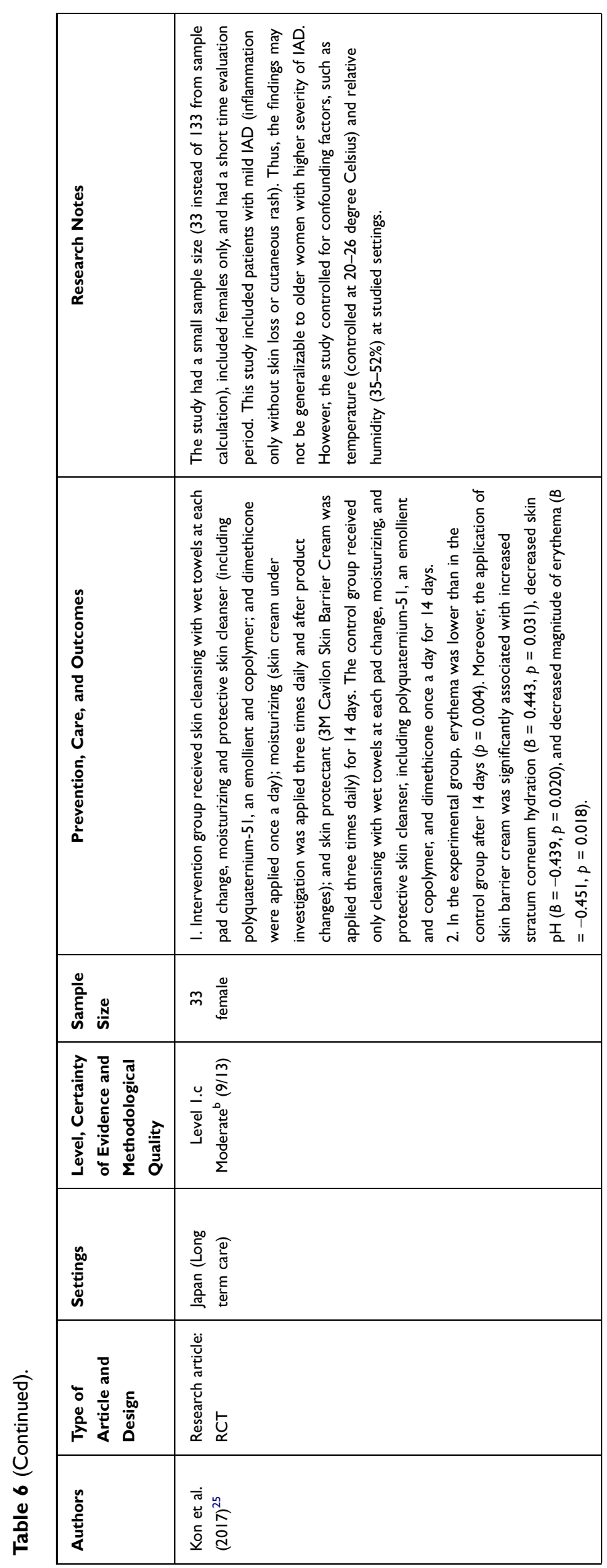




\begin{tabular}{|c|c|}
\hline 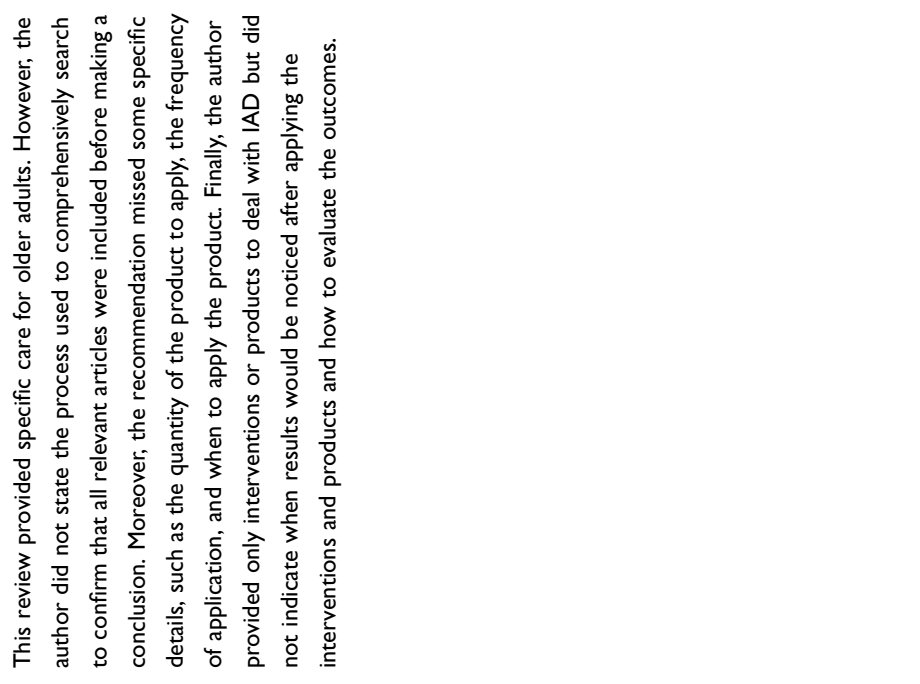 & 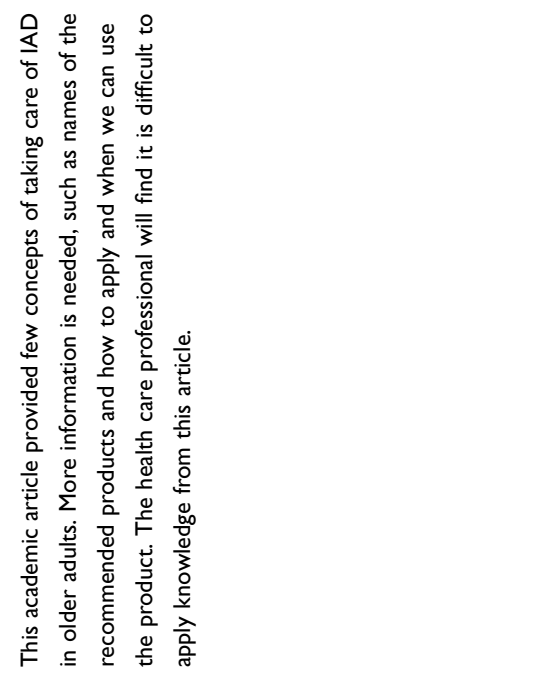 \\
\hline 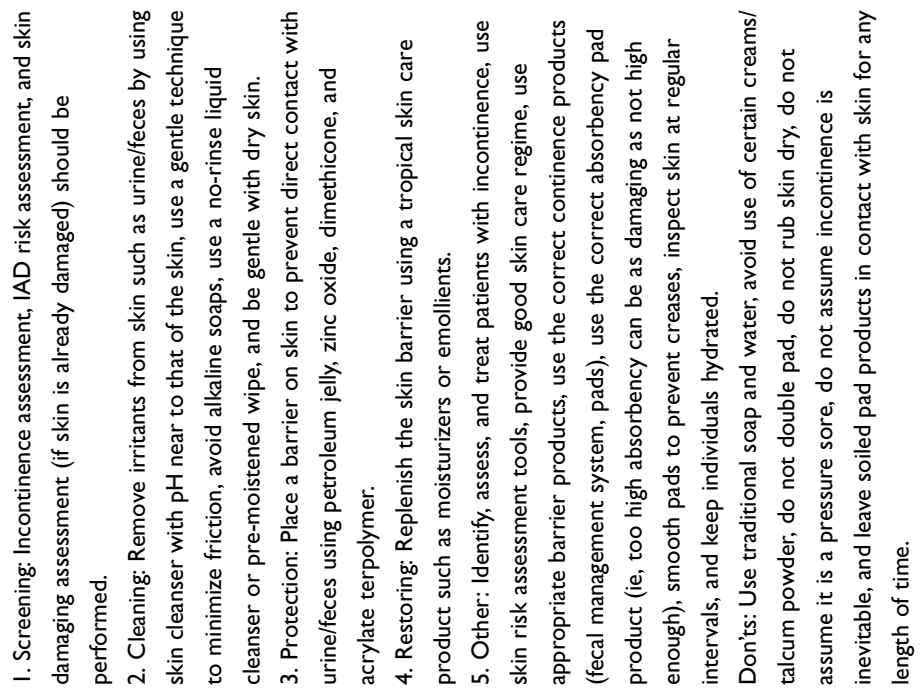 & 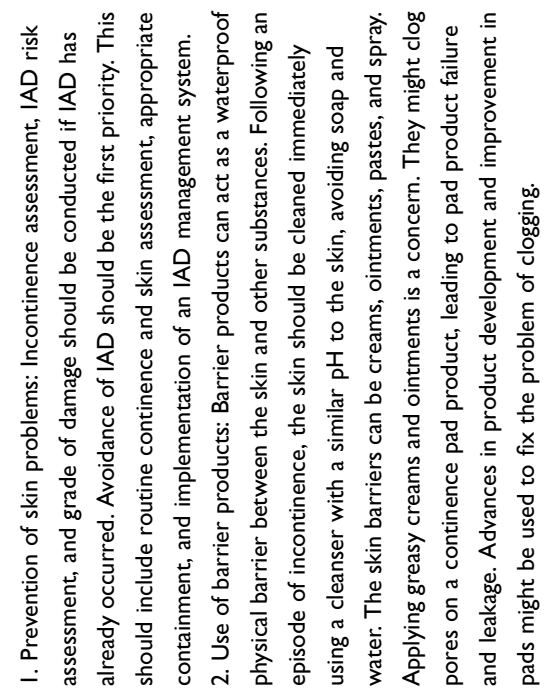 \\
\hline & 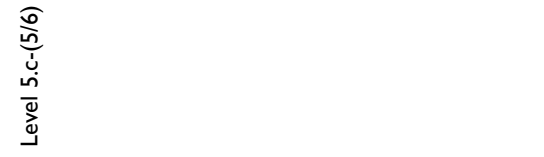 \\
\hline 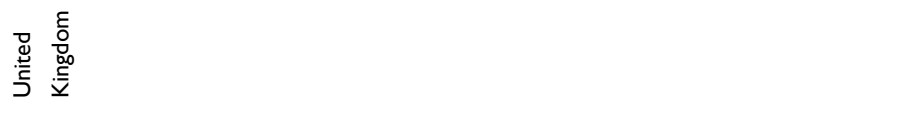 & 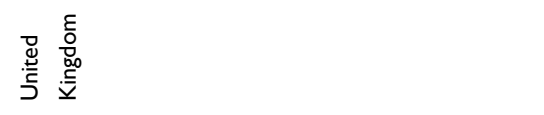 \\
\hline 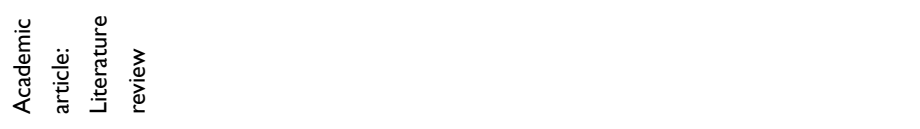 & 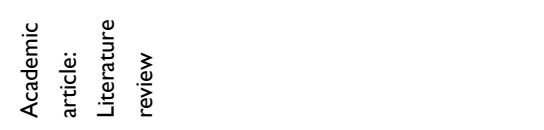 \\
\hline 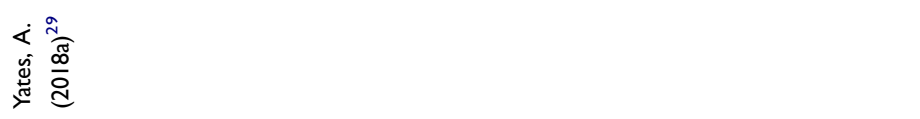 & 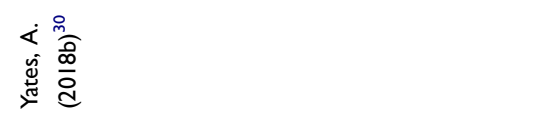 \\
\hline
\end{tabular}




\begin{tabular}{|c|c|c|}
\hline & 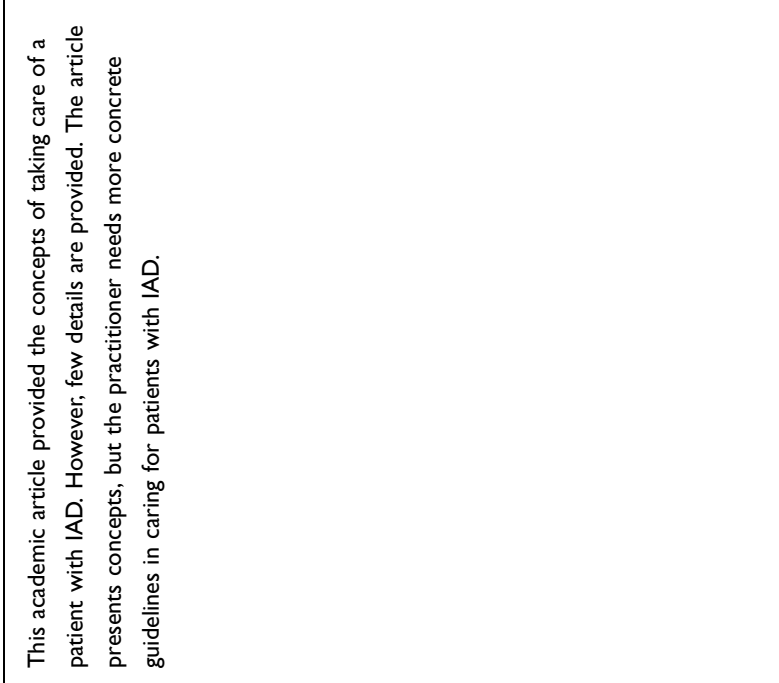 & 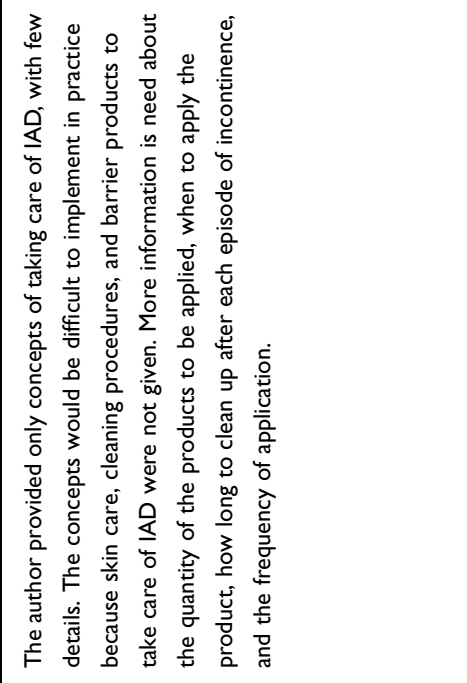 \\
\hline 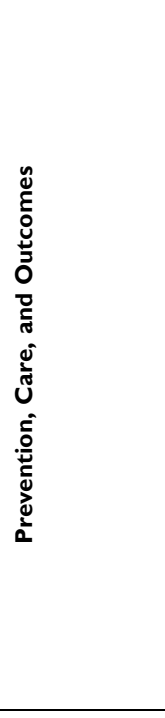 & 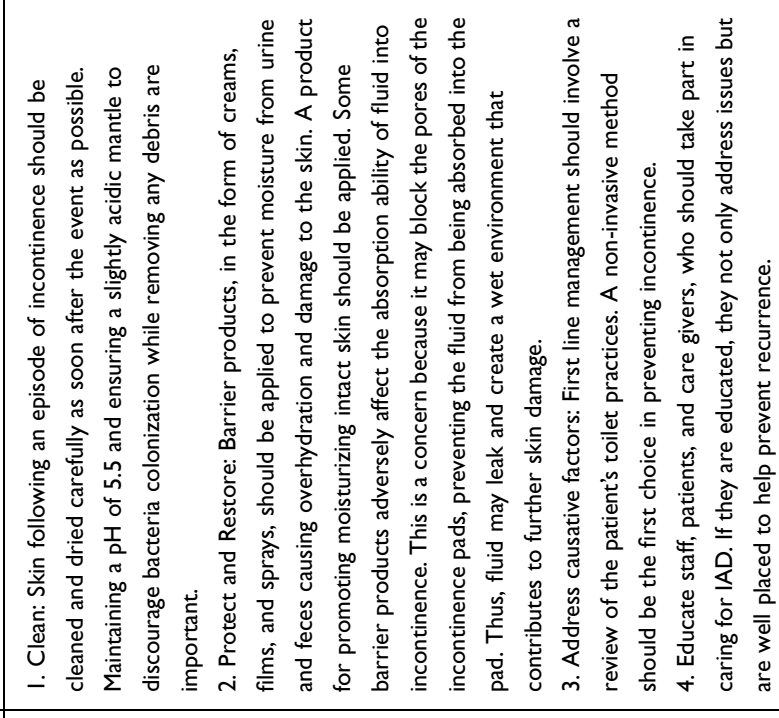 & 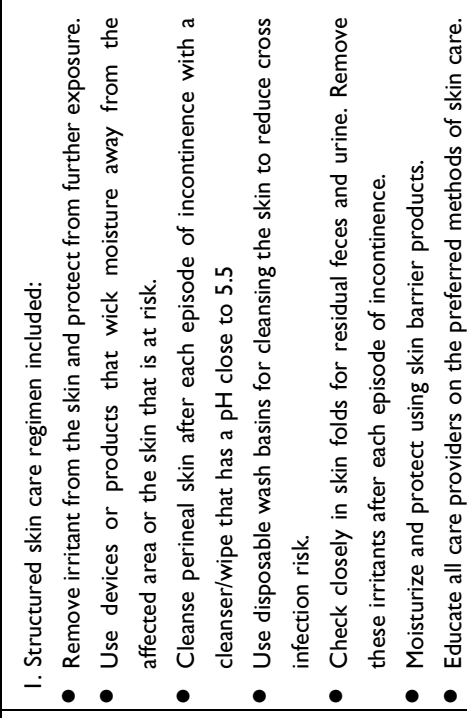 \\
\hline 造。 & . & . \\
\hline 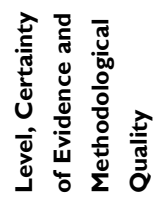 & 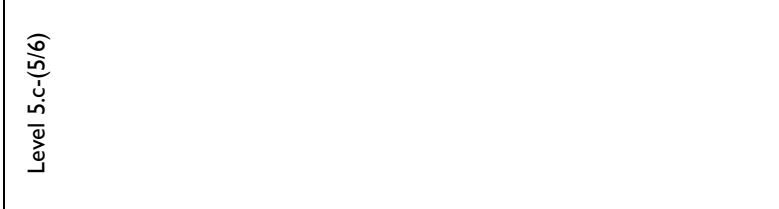 & 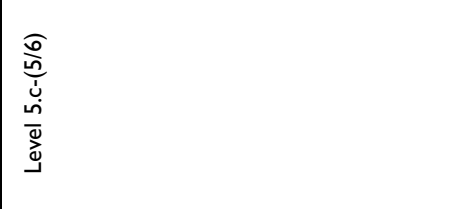 \\
\hline & 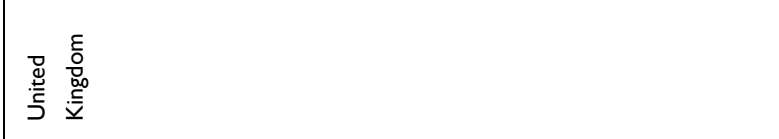 & 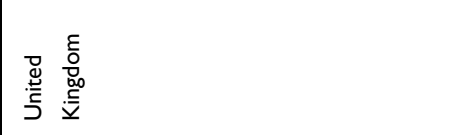 \\
\hline 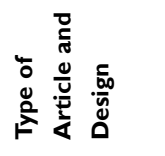 & 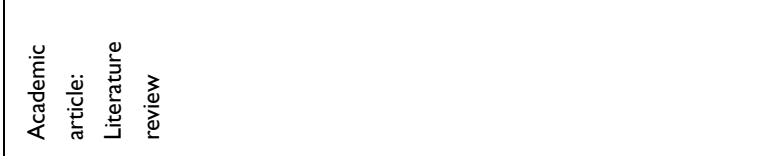 & 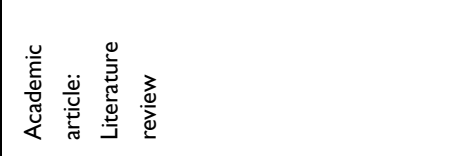 \\
\hline $\begin{array}{l}\frac{n}{0} \\
\frac{0}{4}\end{array}$ & 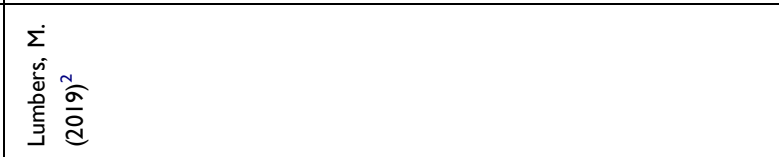 & 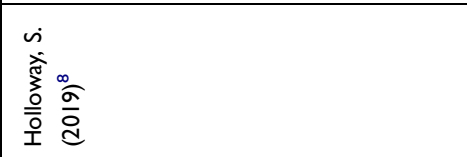 \\
\hline
\end{tabular}




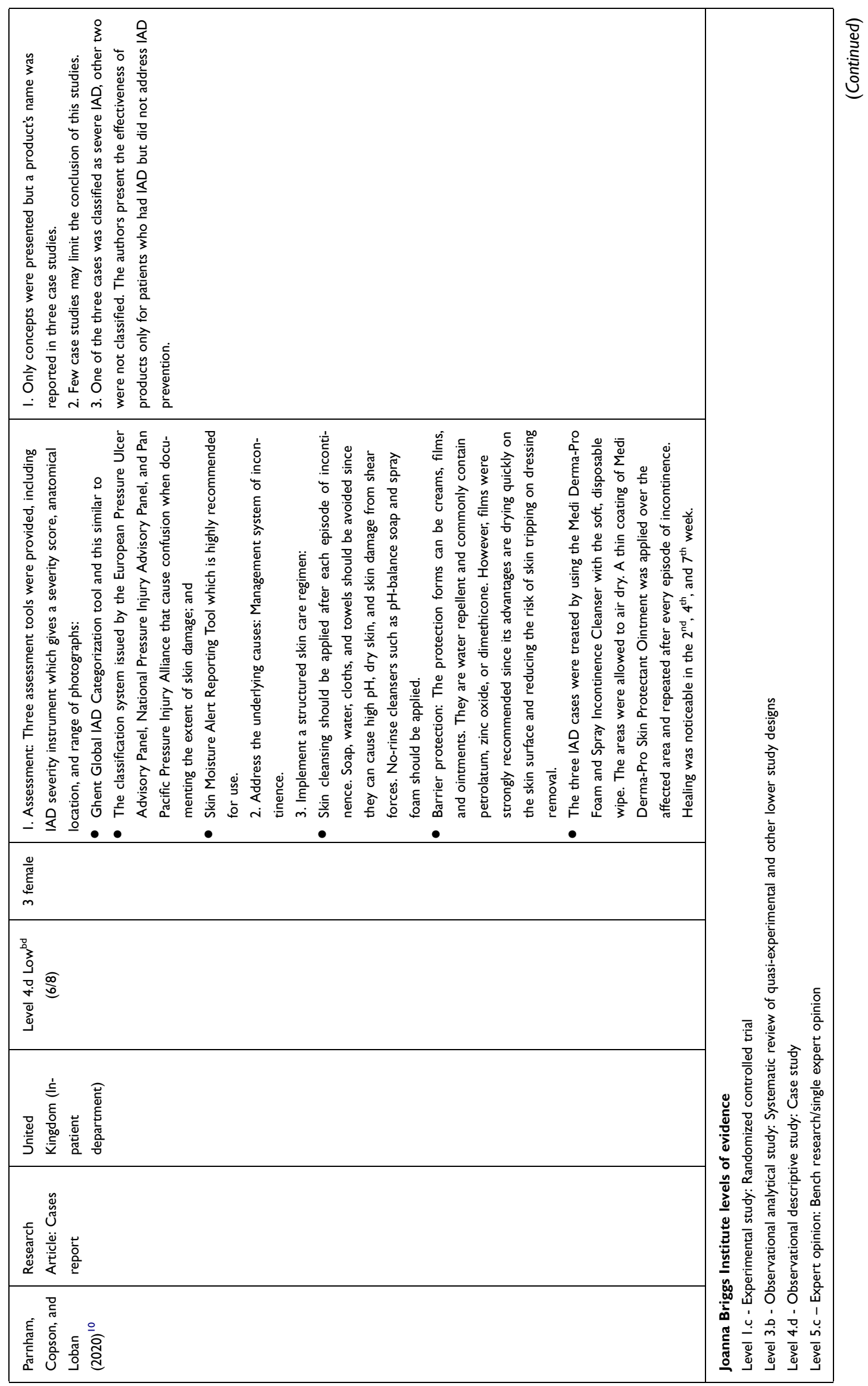


sprays. ${ }^{2,10,30}$ There were seven articles reporting skin barrier products. Some authors reported only ingredients contained in the products, ${ }^{26,27,29}$ but others gave the commercial names of the products. ${ }^{1,10,25,28}$

The authors did not always indicate the quantity that was to be applied for treatment or prevention. However, some reported the frequency and duration of use, such as at every episode of incontinence, three time a day (as needed), or applied for 14 days. ${ }^{26}$ The authors recommended that the barrier products might be of concern because they could block the pores of the incontinence pads and prevent absorption of moisture. ${ }^{2}$ Corcoran and Woodward (2013) reported that zinc oxide was the most effective in preventing skin irritation, ${ }^{26}$ however, Parnham, Copson and Loban, (2020) pointed out that spray films were the strongest recommended product because they dried quickly on the skin surface and reduced the risk of skin tearing on dressing removal. ${ }^{10}$

\section{Body Positioning}

Body positioning is a method to decrease the surface area of skin irritation. The purpose of this method for IAD prevention and care (decreasing area of irritation and promoting air flow) differs from preventing pressure ulcers (decreasing pressure force on buttocks). One review showed that body positioning can be used to prevent IAD. Iamma (2017) recommended placing the person on either the right or left side instead of on the back to prevent and decrease the severity of IAD. ${ }^{27}$ These positions could be used to decrease the area of skin contact from urine and feces, which are the major causes of chemical irritation that induce IAD occurrence and severity progression.

\section{Nutrition Promotion}

Tissue recovery is faster when supported by nutrient-rich sources, especially protein. Only one article reported that nutrition can be a significant factor to prevent IAD and promote recovery from IAD. Kliangprom and Putivanit (2017) recommended that foods high in protein should be promoted to both prevent patients from IAD and recover patients who already had IAD for faster wound healing. ${ }^{28}$

\section{Health Education and Training}

Health education is one strategy for training and implementing health promotion and disease prevention programs, such as IAD. Training refers to the teaching and 
learning activities necessary to help participants apply the requisite knowledge, skills, abilities, and attitudes needed to prevent IAD and care for those patients. The essentials of IAD health education and training was found in two articles. Two authors strongly recommended that persons who give care to older adults should be educated and trained about skin care. ${ }^{2,8}$ These should include staff, patients, and caregivers. The staff and caregivers are not only positioned to address the issues but also are well placed to observe and prevent recurrence of IAD. ${ }^{2}$

\section{Outcomes Evaluation}

Outcome evaluation is the last process after implementing prevention and care strategies for IAD patients. It should be used to confirm goal achievement and guide what the next steps that should be taken. The importance of outcome evaluation processes were found in six articles. 1,10,24-26,28 Based on the specific purposes of the articles and the variety of outcomes that were studied, three categories of outcome evaluation were identified: use of statistical measures, medical indicators, and research instruments. Outcomes could be evaluated by using statistical measures, such as incidence and prevalence rates of IAD; medical indicators, such as stratum corneum hydration and skin $\mathrm{pH}$ surface; and research instrument evaluation, such as Incontinence Associated Dermatitis and its Severity Instrument (IADS) and Ghent Global IAD Categorization Tool (GLOBIAD). Using these methods of outcome evaluation, researchers chose the following times to measure the outcome: at 6 hours, ${ }^{26} 14$ days, ${ }^{10,25}$ and at 24 and 49 days ${ }^{10}$ after initiating their interventions. However, not all authors indicated the timing of an evaluation.

\section{Outcomes}

The outcome is the result or effect of an action, situation, or event. This includes something that follows as a result or consequence after completing interventions or strategies for the prevention of IAD and care of those patients. Five studies reported outcomes after implementing their interventions. $^{1,10,24-26}$ Skin integrity, skin texture, pain, comfort and assurance of efficacy to the individual were improved after cleaning by warm water, patting the area dry, and applying LBF Barrier Cream. ${ }^{1}$ The number of patients was higher and actual recovery time was faster from IAD after using an improved apertured film plus feminine pad than the patients who used conventional products. However, moisture content and skin $\mathrm{pH}$ were similar in both groups. ${ }^{24}$ Skin irritation was prevented by a zinc oxide product, and hydration was promoted by the use of glycerin. ${ }^{26}$ The magnitude of erythema and skin $\mathrm{pH}$ was decreased, but stratum corneum hydration was increased after applying a skin barrier cream. ${ }^{25}$ Finally, healing was noticeable in the 2 nd, 4 th, and 7 th weeks after applying Medi Derma-Pro Foam and Spray Incontinence Cleanser with the soft and disposable wipe. ${ }^{10}$

\section{Discussion}

We found that assessment was the first activity of most prevention and care strategies. Assessment is the first thing that a health care professional should do to identify risk and severity levels of IAD before developing a care plan. ${ }^{13}$ This should cover both risk and dermatitis assessments. De Meyer et al (2019) reported on 10 instruments for measuring erythema associated with IAD in all age groups. ${ }^{31} \mathrm{We}$ found seven instruments for use in older adults. Although there is some overlap between what they reported and those we found, the seven instruments might be better suited for assessing IAD in older adults because the authors recommended, approved, and used them in this vulnerable population.

Incontinence management for urinary and fecal incontinence should be a primary focus following assessment because both are the two main causes of IAD. ${ }^{17}$ Fecal collection devices significantly reduce the incidence of IAD. Examples include anal pouch collection devices, anal pouches connected to negative-pressure suction devices, anal catheter/tube collection devices, and anal catheters/tubes connected to negative-pressure suction devices. ${ }^{17}$ A retraining Foley catheter for urine incontinence is optional. However, non-invasive strategies should always be placed as the first choice of use. ${ }^{2}$ Examples of non-invasive strategies are reviewing the patients' toileting habits, wearing a condom catheter, using a soft pad, and putting on a diaper. ${ }^{2,27}$ Pads are more advantageous than diapers because they promote airflow and avoid chemical irritation form urine and feces.

The recommended $\mathrm{pH}$ cleansing agent should be between 4.0 and 6.8. A low $\mathrm{pH}$ has been recommended in younger populations. ${ }^{9,14}$ An acid skin $\mathrm{pH}(4-4.5)$ keeps the resident bacterial flora attached to the skin. Moreover, the acidic $\mathrm{pH}$ of the stratum corneum is considered to present an antimicrobial barrier preventing colonization. ${ }^{32,33}$ If the skin becomes more alkaline, its ability to inhibit bacterial growth is compromised. ${ }^{26}$ The $\mathrm{pH}$ of commercially available skin cleansers is generally about 9.0; their frequent use can strip the skin of its natural barrier. ${ }^{26}$ This can cause both IAD and 
secondary infection. Caregivers of older adults with IAD should be educated to select acid mantle products. Finally, different time frames were recommended for cleaning patients after an episode of incontinence. The best recommendation is within 10-15 minutes because IAD can take place when the skin becomes irritated during that period. ${ }^{4}$

Older adults are prone to skin break down because of the previously mentioned aging physiological processes. The use of both skin moisturizing and skin barrier products are strongly recommended..$^{9,14,34,35}$ Specific products include zinc oxide oil, $3 \mathrm{M}^{\mathrm{TM}}$ Cavilon No Sting Barrier Film, no-rinse cleansing foam plus moisturizer, no-rinse $\mathrm{pH}$-balanced liquid cleanser and barrier cream, $3 \mathrm{M}^{\mathrm{TM}}$ Cavilon Durable ${ }^{\mathrm{TM}}$ barrier cream, dimethicone, emollients, and petrolatum containing products. The superiority of one product over the other may be difficult to ascertain,26,34 although Lichterfeld-Kottner et al (2020) recommend that a lower $\mathrm{pH}$ product, especially 4.0, will provide better effects as a skin barrier. ${ }^{9}$ In addition, using a combination of skin moisturizer and skin barrier will provide a more desirable effect of IAD care. ${ }^{35}$

Although nutrition support and repositioning the body (turning) in bed are recommended to sustain skin integrity in older adults, they are not suggested as actions for the adult and pediatric populations. $9,14,34,35$ These two recommendations may be specific to older adults as part of their IAD risk factors. Body areas of irritation in older adults are larger than in the pediatric population, thus positioning in children may not significantly prevent IAD. Because over $8 \%$ of community dwelling older adults and up to $30 \%$ of hospitalized older adults experience malnutrition, nutrition support and promotion are important for cell growth and healing. ${ }^{36}$ These are the reasons why promoting nutrition and turning positioning are specific strategies for prevention and care for older adults with IAD.

Health education and training of staff, patients, and caregivers are important findings in our review of the literature. The same has been reported in the care of adults. ${ }^{35}$ Health education and training increase knowledge in learning the difference between IAD and pressure ulcers. If there is a lack of awareness of the difference in presentation and cause of the two conditions, staff and caregivers may misdiagnose and wrongly apply non-specific interventions. ${ }^{26,35}$ Education and training not only provide prevention and care for IAD, patients and caregivers help observe and report when risk factors are detected, including the early signs of IAD. ${ }^{2,8}$
Outcomes of intervention evaluation for older adults are the same as in other populations..$^{9,14,31,34,35}$ Outcomes may be placed into three categories: statistical measures, medical indicators, and research instrument evaluation based on the specific purposes of the studies and assortment of outcomes. The time frame of outcome evaluation varied among the articles we reviewed, depending on the type of intervention/outcome. Unfortunately, most of the authors did not specify the best time for the appropriate evaluation. A similar conclusion about core outcomes in IAD has been reported elsewhere. ${ }^{35}$ Outcome evaluation of interventions is an area recommended for future study and exploration.

We found five articles that reported outcomes after implementing prevention and care interventions for older adults with IAD. Outcomes were skin integrity, skin texture, skin $\mathrm{pH}$, skin irritation, moisture content or stratum corneum hydration, magnitude of erythema, the number of recovered patients, time of recovery, pain, comfort, and assurance of efficacy to the individual. Major outcomes in our review focused on medical indicators. However, the studies of adult patients included in a systematic review by Beeckman et al (2016) focused on statistical measures, such as the number of participants with and without IAD, and the cost of treatment and care. ${ }^{12}$ Finally, we found the same limitations and conclusions that Beeckman et al (2016) drew in their research. The available evidence on prevention and care, especially for skin cleansing, skin moisturizing, and skin barrier products, is limited. More research needs to be conducted to make more informed conclusions.

\section{Strengths and Limitations}

This systematic review included recommendations from international studies and perspectives. The articles provided specific prevention and care strategies applicable to the older population. However, it was difficult for us to conclude which interventions or medical products had superior effectiveness because of the heterogeneity of measurement tools, designs, outcomes, time points, and interventions. Moreover, most of the articles did not indicate how to apply the products, the quantity to be applied, the frequency of application, and when to apply. Therefore, implications for practice are quite limited.

\section{Conclusions and Recommendations}

We searched eight databases for empirical articles and applied a narrative method to report findings about the 
prevention and care of IAD. Out of 17,631 initial articles, 11 articles were selected for final review. Specific prevention and care strategies for older adults with IAD included using specific assessment tools, applying skin cleansing $\mathrm{pH}$ from 4.0 to 6.8 , body positioning, and promoting food with high protein. Other strategies we identified were similar to those used with adult patients. Health care professionals and others who care for older adults should be educated about the prevention and care of IAD so that they are able to provide specific interventions and quality of care for this population. If a commercial product is used, an acid pH should be determined, and the instructions should be followed carefully. Research needs to be conducted to establish the most effective cleanser, skin moisturizer, and skin barrier products on the market. For this, RCTs on product effectiveness for prevention and care of IAD among older adults are highly recommended. Finally, because evaluation is an important part of prevention and care for IAD, the questions of when and how to evaluate the interventions' outcomes require special consideration and attention in future research.

\section{Acknowledgments}

We thank those who contributed to this systematic review for their collaboration and support. Special appreciation is extended to Dr. Andrew C. Mills for reviewing early drafts.

\section{Funding}

Grant Information: this work was financially supported by the Research and Training Center of Enhancing Quality of Life of Working Age People (Grant Number QWFM64003), Research Cluster in Gerontological Nursing, Faculty of Nursing, Khon Kaen University (Grant Number FM641-2-2-3) and Research and Graduate Studies, Khon Kaen University (Grant Number GS64-1-2-2-3). Appreciation is extended to these research cluster and training centers for making the research possible.

\section{Disclosure}

The authors report no conflicts of interest for this work and declare that there is no conflict of interest regarding the publication of this paper.

\section{References}

1. Beldon P. Incontinence-associated dermatitis: protecting the older person. Br J Nurs. 2012;21(7):402-407. doi:10.12968/bjon.2012.21.7.402
2. Lumbers M. How to manage incontinence-associated dermatitis in older adults. British Journal of Community Nursing. 2019;24(7):332337. doi:10.12968/bjen.2019.24.7.332

3. Gray M, Beeckman D, Bliss DZ, et al. Incontinence associated dermatitis: a comprehensive review and update. J Wound Ostomy Continence Nurs. 2012;39(1):61-74. doi:10.1097/WON.0b013 e31823fe246

4. Nix D, Haugen V. Prevention and management of incontinenceassociated dermatitis. Drugs Aging. 2010;27(6):491-496. doi:10.2165/11315950-000000000-00000

5. Leblebiciglu Y, Khorshid L, Ondogan Z, Ozturk G. Development of a new incontinence containment product and an investigation of its effect on perineal dermatitis in patients with fecal incontinence: a pilot study in women. Wound Manag Prev. 2019;65(1):20-27. doi:10.25270/WMP/2019.1.2027

6. Hödl M, Blanař V, Amir Y, Lohrmann C. Association between incontinence, incontinence-associated dermatitis and pressure injuries: a multisite study among hospitalized patients 65 years or older. Australas J Dermatol. 2020;61(1):e144-e146. doi:10.1111/ ajd. 13163

7. Gray M, Giuliano KK. Incontinence-associated dermatitis, characteristics and relationship to pressure Injury: a multisite epidemiologic analysis. J Wound Ostomy Continence Nurs. 2018;45(1):63-67. doi:10.1097/WON.0000000000000390

8. Holloway S. Skin considerations for older adults with wounds. $\mathrm{Br} J$ Community Nurs. 2019;24(Suppl 6):S15-S19. doi:10.12968/ bjen.2019.24.Sup6.S15

9. Lichterfeld-Kottner A, El Genedy M, Lahmann N, Blume-Peytavi U, Büscher A, Kottner J. Maintaining skin integrity in the aged: a systematic review. Int J Nurs Stud. 2020;103:1-23. doi:10.1016/j. ijnurstu.2019.103509

10. Parnham A, Copson D, Loban T. Moisture-associated skin damage: causes and an overview of assessment, classification and management. $B r \quad J \quad$ Nurs. 2020;29(12):S30-S37. doi:10.12968/ bjon.2020.29.12.S30

11. Raepsaet C, Fourie A, Hecke AV, Verhaeghe S, Beeckman D. Management of incontinence-associated dermatitis: a systematic review of monetary data. Int Wound J. 2021;18(1):79-94. doi:10.1111/iwj.13496

12. Beeckman D, Damme NV, Schoonhoven L, et al. Interventions for preventing and treating incontinence-associated dermatitis in adults. Cochrane Database Syst Rev. 2016;11(11):CD011627. doi:10.1002/ 14651858.CD011627.pub2

13. Geraldo MS, Cleber AR, Flávio DM, Ronaldo AJ, Rosimar Aparecida AD, Amanda Gabriele T. Algorithms for prevention and treatment of incontinence-associated dermatitis. Revista Estima. 2020;18:1-10. doi:10.30886/estima.v18.837 IN

14. Lim YSL, Carville K. Prevention and management of incontinenceassociated dermatitis in the pediatric population. J Wound Ostomy Continence Nurs. 2019;46(1):30-37. doi:10.1097/WON.000000 0000000490

15. Pather P, Dip G, Cert G, Hines S. Best practice nursing care for ICU patients with incontinence-associated dermatitis and skin complications resulting from fecal incontinence and diarrhea. Int J Evid Based Healthc. 2016;14:15-23. doi:10.1097/XEB.0000000000000067

16. Van Wissen K, Blanchard D. Preventing and treating incontinenceassociated dermatitis in adults. Br J Community Nurs. 2019;24(1):3233. doi:10.12968/bjen.2019.24.1.32

17. Yan Z, Leng M, Guo J, Duan J, Zhiwen W. The effectiveness of faecal collection devices in preventing incontinence-associated dermatitis in critically ill patients with faecal incontinence: a systematic review and meta-analysis. Aust Crit Care. 2021;34(1):103-112. doi:10.1016/j.aucc.2020.04.152

18. Aromataris E, Munn Z. Joanna Briggs Institute Reviewer's Manual. Adelaide: Joanna Briggs Institute [cited 20 February 2018.]. 2017. Available from: https://reviewersmanual.joannabriggs.org/. Accessed 4 October 2021. 
19. Aromataris E, Fernandez R, Godfrey C, Holly C, Kahlil H, Tungpunkom P. Summarizing systematic reviews: methodological development, conduct and reporting of an umbrella review approach. Int J Evid Based Healthc. 2015;13(3):132-140. doi:10.1097/ XEB.0000000000000055

20. Tufanaru C, Munn Z, Aromataris E, Campbell J, Hopp L. Chapter 3: systematic reviews of effectiveness. Aromataris E, Munn Z, editors. JBI Manual for Evidence Synthesis: 2020. Available from https:// synthesismanual.jbi.global. Accessed October 4, 2021.

21. McArthur A, Klugarova J, Yan H, Florescu S. Innovations in the systematic review of text and opinion. Int $J$ Evid Based Healthc. 2015;13(3):188-195. doi:10.1097/XEB.0000000000000060

22. Moola S, Munn Z, Tufanaru C, et al. Chapter 7: systematic reviews of etiology and risk. Aromataris E, Munn Z, editors. JBI Manual for Evidence Synthesis: 2020. Available from https://synthesismanual.jbi. global. Accessed October 4, 2021.

23. Schünemann H, Brożek J, Guyatt G, Oxman A, GRADE Handbook; 2013. Available from: https://gdt.gradepro.org/app/handbook/handbook. h t m 1 ? fbc 1 id = I w A R 04097 y X I e J A 1 u 6 k y z M g w e S VpFcA0uJsIpWXRwzKQhPBIBJ9aX3u7UN94. Accessed October 4, 2021.

24. Sugama J, Sanada H, Shigeta Y, Nakagami G, Konya C. Efficacy of an improved absorbent pad on incontinence-associated dermatitis in older women: cluster randomized controlled trial. BMC Geriatr. 2012;12(22):1-7. doi:10.1186/1471-2318-12-22

25. Kon Y, Ichikawa-Shigeta Y, Luchi T, et al. Effects of a skin barrier cream on management of incontinence-associated dermatitis in older women. J Wound Ostomy Continence Nurs. 2017;44(5):481-486. doi:10.1097/WON.0000000000000353

26. Corcoran E, Woodward S. Incontinence-associated dermatitis in the elderly: treatment option. Br J Nurs. 2013;22(8):1234-1239. doi:10.12968/bjon.2013.22.8.450

27. Iamma W. Knowledge for caregivers: skin care for older persons with bowel incontinence. Thai J Nurs Midwifery Pract. 2017;4(1):55-58.
28. Kliangprom J, Putivanit S. Prevention of skin breakdown in the older person. South Coll Netw J Nurs Public Health. 2017;4(3):249-258.

29. Yates A. Incontinence-associated dermatitis in older people: prevention and management. Br J Community Nurs. 2018a;23(5):218-224. doi:10.12968/bjen.2018.23.5.218

30. Yates A. Preventing skin damage and incontinence-associated dermatitis in older people. Br J Nurs. 2018b;27(2):76-77. doi:10.12968/ bjon.2018.27.2.76

31. De Meyer D, Gabriel S, Kottner J, et al. Outcome measurement instruments for erythema associated with incontinence-associated dermatitis: systematic review. J Adv Nurs. 2019;75:2393-2417. doi:10.1111/jan.14102

32. Lambers H, Piessens S, Bloem A, Pronk H, Finkel P. Natural skin surface $\mathrm{pH}$ is on average below 5 , which is beneficial for its resident flora. Int J Cosmet Sci. 2006;28(5):359-370. doi:10.1111/j.14672494.2006.00344.x

33. Proksch E. $\mathrm{pH}$ in nature, humans and skin. $J$ Dermatol. 2018;45:1044-1052. doi:10.1111/1346-8138.14489

34. Priscilla P, Sonia H, Kate K, Fiona C. Effectiveness of topical skin products in the treatment and prevention of incontinence-associated dermatitis: a systematic review. JBI Database System Rev Implement Rep. 2017;15:1473-1496. doi:10.11124/JBISRIR-2016-003015

35. Van den Bussche K, Kottner J, Beele H, et al. Core outcome domains in incontinence-associated dermatitis research. $J$ Adv Nurs. 2018;74:1605-1617. doi:10.1111/jan.13562

36. Griffin A, O’Neill A, O’Connor M, Ryan D, Tierney A, Galvin R. The prevalence of malnutrition and impact on patient outcomes among older adults presenting at an Irish emergency department: a secondary analysis of the OPTI-MEND trial. BMC Geriatr. 2020;20:455. doi:10.1186/s12877-020-01852-w

37. Page MJ, McKenzie JE, Bossuyt PM, et al. The PRISMA 2020 statement: an updated guideline for reporting systematic reviews. BMJ. 2021;372:n71. doi:10.1136/bmj.n71
Journal of Multidisciplinary Healthcare

\section{Publish your work in this journal}

The Journal of Multidisciplinary Healthcare is an international, peerreviewed open-access journal that aims to represent and publish research in healthcare areas delivered by practitioners of different disciplines. This includes studies and reviews conducted by multidisciplinary teams as well as research which evaluates the results or conduct of such teams or healthcare processes in general. The journal

\section{Dovepress}

covers a very wide range of areas and welcomes submissions from practitioners at all levels, from all over the world. The manuscript management system is completely online and includes a very quick and fair peer-review system. Visit http://www.dovepress.com/testimonials. php to read real quotes from published authors. 